\title{
Article
}

\section{Arizona Twin Project: Specificity in Risk and Resilience for Developmental Psychopathology and Health}

\author{
Kathryn Lemery-Chalfant, Veronica Oro, Gianna Rea-Sandin, Samantha Miadich, Emma Lecarie, Sierra Clifford, \\ Leah D. Doane and Mary C. Davis \\ Department of Psychology, Arizona State University, Phoenix, AZ, USA
}

\begin{abstract}
The Arizona Twin Project is an ongoing longitudinal study designed to elucidate gene-environment interplay underlying the development of risk and resilience to common mental and physical health problems during infancy, childhood and adolescence. Specificity of risk is carefully examined across mental and physical health and how these influences vary across socioeconomic and sociocultural environments. Participants are a sample of approximately 700 twins (31\% Latinx) recruited from birth records in the state of Arizona, USA. Twins are $32 \%$ monozygotic twins, 36\% same-sex dizygotic (DZ), 32\% opposite-sex DZ, currently 10-11 years of age. Primary caregivers were interviewed on twins' development and early physical and social environments when twins were 1,2 and 5 years of age. In-depth objective measurement commenced in middle childhood, with in-person assessments at 8-11 years of age, with plans to continue to follow the sample across adolescence. Middle childhood measures focus on children's physical and mental health, including diurnal cortisol, actigraphy-based measures of sleep and activity, cold pressor task assessing acute pain, and reaction time tasks assessing executive functioning. Preliminary findings illustrate that objective assessments of children's health are highly heritable, but they do not always share genetic etiology with more commonly used subjective assessments. Exposure to early adversity moderates genetic influences on both executive functioning and health, with higher heritability typically seen under adverse conditions. Future directions include an examination of how pubertal stage affects genetic and environmental influences on diurnal cortisol, sleep, chronic pain, and mental health.
\end{abstract}

Keywords: Latinx; developmental psychopathology; sleep; pain; cortisol

(Received 30 August 2019; accepted 16 September 2019; First Published online 23 December 2019)

The overarching goal of the Arizona Twin Project addresses a central developmental question - how resilience (the capacity to bounce back following adversity) develops and affects the impact of early risk on child physical health and common mental health disorders, such as attention-deficit hyperactivity disorder, conduct problems, anxiety and depression. The study begins in infancy and longitudinally follows the twins across childhood, with plans to continue to follow them across adolescence into adulthood. There is an urgent need to understand these processes, as health problems continue to rise among children and adolescents, with adolescents spending less time sleeping, having higher body mass, reporting more depression, self-harm, conduct problems and peer problems (Keyes et al., 2015; Patalay \& Gage, 2019). By focusing on components of early resilience within a representative twin study, our goal is to elucidate processes by which youth bounce back after adversity and grow to be healthy and competent individuals.

The main focus of the Arizona Twin Project involves understanding the genetic and environmental influences within and across multiple domains of development. The Arizona Twin Project spans individual, family, neighborhood and sociocultural

Author for correspondence: Kathryn Lemery-Chalfant, Email: Kathryn.Lemery@asu.edu Cite this article: Lemery-Chalfant $\mathrm{K}$, Oro V, Rea-Sandin G, Miadich S, Lecarie E, Clifford S, Doane LD, and Davis MC. (2019) Arizona Twin Project: Specificity in Risk and Resilience for Developmental Psychopathology and Health. Twin Research and Human Genetics 22: 681-685, https://doi.org/10.1017/thg.2019.113 levels of analysis, with an emphasis on sleep, pain, physiological stress processes, mental and physical health, and academic competence. Importantly, our ethnically diverse sample is representative of the state of Arizona, thus affording the opportunity to consider the role of culture in the etiology of various child outcomes. In sum, the Arizona Twin Project utilizes behavior genetic methods in order to understand risk and resilience processes that promote healthy development.

\section{Recruitment and Retention}

The Arizona Twin Project is an ongoing longitudinal study involving 350 pairs of young twins, 32\% monozygotic (MZ) twins, $36 \%$ same-sex dizygotic (DZ), 32\% opposite-sex DZ, currently $10-11$ years of age. Twin participants are diverse in terms of race/ethnicity ( $>31 \%$ Latinx) and socioeconomic status (SES) (45.8\% below middle class). Income ranges from less than US $\$ 20 \mathrm{~K}$ to over $\$ 100 \mathrm{~K}$, with a median of $\$ 50-70 \mathrm{k}$. Parental education ranges from less than a high school degree to a professional degree, with mean education of 'some college'.

Families were recruited when twins were 10 months of age through collaboration with the Arizona State Department of Health Services, who sent recruitment letters (in English and Spanish) to mothers ( $>18$ years) who had given birth to live twins in an Arizona hospital between July 2007 and July 2008. The letter included a postage-paid return letter where families could indicate 
their interest in participating, and follow-up letters were mailed 1 month after the first letter if we did not receive a response. Informed consent was obtained prior to all interviews, and participants were monetarily compensated at each measurement occasion.

We have regular contact with the families (i.e., sending our quarterly Arizona Twin Project Newsletter and birthday cards), which keeps contact information current, and we provide flexibility in scheduling assessments. Attrition from infancy to 2, 5, 8, 9 and 10 years has been $<16 \%$, with those who participated only at 1 year similar to other families on our key health variables.

The Zygosity Questionnaire for Young Twins (Goldsmith, 1991) was used to determine whether twins were identical or fraternal. This questionnaire yields over $95 \%$ agreement with zygosity determined via genotyping (Forget-Dubois et al., 2003; Price et al., 2000). Zygosity was further verified with infant birth medical records and photographs taken at home visits. In addition, we genotyped the $3 \%$ most difficult cases.

\section{Middle Childhood Data Collection: 8-11 Years of Age}

The previous Arizona Twin Project overview describes findings from the prenatal, infancy and early childhood assessments (Lemery-Chalfant et al., 2013). Table 1 lists completed assessments at 8-11 years. Demographic variables such as SES (including subjective and objective assessments and income-to-needs ratio), food insecurity, race/ethnicity and number of adults and children in the home are assessed at each occasion. All measures have been used in previous research and have acceptable levels of reliability and validity with White samples. Whenever possible, we used measures that have also been used with Latinx samples, and we statistically examine measurement equivalence across ethnic groups.

\section{General Home Visit Protocol}

After obtaining primary caregiver consent and youth assent, the primary caregiver and each twin (first one randomly selected, then the other) participate in a videotaped parent-child discussion task, and staff conduct the HOME assessment of cognitive, socialemotional and physical support within the home environment (Bradley et al., 2000). Twins independently complete working memory and executive functioning tasks with staff (i.e., Digit Span; Wechsler, 2003) and on laptop computers using the Psychology Experiment Building Language (Mueller, 2013). Tasks include the continuous performance task (Conners, 2000) and the Eriksen flanker task (Eriksen \& Eriksen, 1974). The cold pressor task (Von Baeyer et al., 2005) is used to assess acute pain tolerance, repeated with and without the primary caregiver present. Objective assessments of health are also obtained, including measures of lung capacity, grip strength, balance and BMI. Home visits last $2-3 \mathrm{~h}$ including breaks to minimize fatigue.

\section{Actigraphy Assessment of Sleep and Activity}

The Motionlogger Micro Watch, a wrist-based accelerometer, (Ambulatory Monitoring, Inc., Ardsley, NY, USA) is worn on the children's nondominant wrist for 7 days and nights. These devices measure motion in 1-min epochs using a zero-crossing mode. Sleep measures extracted include (1) sleep midpoint time (halfway point between wake and bed time), (2) hours of sleep (sleep time excluding all periods of wakefulness during total sleep period), (3) sleep efficiency (time asleep divided by time in bed) and (4) sleep latency (minutes in bed before falling asleep).
Indicators of variability are also constructed. Activity measures include (1) mean duration of wake periods, (2) mean activity level, (3) moderate or vigorous activity (reaching activity counts above age-specified cutoffs) and (4) sedentary activity.

\section{Reports of Chronic Pain and Assessments of Acute Pain}

Primary caregivers and twins both report on child recurring pain in the last 3 months by reporting on the frequency of pain in different body locations on a 1 (never/rarely) to 5 (about every day) scale. Additionally, caregivers complete survey assessments of clinical pain in five locations for each twin: headache, stomachache, lower back pain, widespread pain and temporomandibular pain (Dionne et al., 2008; Drossman, 2016; Dworkin et al., 1992; Headache Classification Subcommittee of the International Headache Society, 2004; Wolfe et al., 2010). Acute pain is assessed with the cold pressor task, during which children immerse their hand in ice cold water $\left(50^{\circ} \pm 1^{\circ}\right.$ Fahrenheit) and keep it underwater for as long as they can (up to $4 \mathrm{~min}$ ). Each twin rates their pain after the task via the Faces of Pain Scale-Revised (Hicks et al., 2001) and the Facial Affective Scale (McGrath et al., 1985). Twins complete this task twice and are randomized to complete their first trial either alone or with their primary caregiver.

\section{Preliminary Findings}

The previous Arizona Twin Project overview describes findings from the infancy and early childhood assessments (LemeryChalfant et al., 2013). We have begun to analyze data from the middle childhood assessments (8-11 years) and highlight a few recent findings below.

\section{Sleep and Weight}

Associations between sleep duration and increased body weight have been consistently reported by both cross-sectional and longitudinal studies (Magee \& Hale, 2012), yet little is known regarding potential underlying mechanisms. We tested the extent to which associations between sleep and weight indicators were genetically or environmentally mediated. Results indicated that associations were explained by shared additive genetic factors $(3 \%-17 \%$ of variance), suggesting that a common, underlying set of genes likely explains relations between sleep problems and high weight and adiposity in children (Breitenstein et al., 2018). However, links between parent-reported and objective sleep indicators were primarily accounted for by shared environmental factors $(5 \%-65 \%$ of variance), suggesting that subjective and objective measures may capture different traits (Breitenstein et al., 2019). Selfregulatory effortful control was also linked with both sleep and weight indicators, such that links between effortful control and objective sleep ( $1 \%-3 \%$ of variance) and weight indicators $(2 \%$ of variance) were explained by shared additive genetics, whereas the association between effortful control and parent-reported sleep was explained by shared environmental factors ( $5 \%$ of variance; Breitenstein, 2019).

\section{Impulsivity and Sleep}

Impulsivity has been associated with shorter sleep duration among children (Gruber et al., 2012); however, the underlying mechanisms are again unclear. We examined whether associations between impulsivity and objectively assessed sleep duration and efficiency were genetically or environmentally influenced. Results indicated common genetic influences and unique environmental 
Table 1. Arizona Twin Project middle childhood assessments

\begin{tabular}{|c|c|}
\hline Construct & Source \\
\hline \multicolumn{2}{|l|}{ Socioeconomic environment } \\
\hline Chaotic and unsafe home environment & P, Obs \\
\hline Family routines & $\mathrm{P}$ \\
\hline Daily hassles, family stress and social support & $\mathrm{P}$ \\
\hline Family structure and transitions & $\mathrm{P}$ \\
\hline $\begin{array}{l}\text { Family socioeconomic, education and occupational } \\
\text { status }\end{array}$ & $P$ \\
\hline Family economic hardship & $\mathrm{P}$ \\
\hline Food insecurity & $\mathrm{P}$ \\
\hline \multicolumn{2}{|l|}{ Sociocultural environment } \\
\hline Acculturation/enculturation (Latinx subsample only) & $\mathrm{P}$ \\
\hline Cultural values and behaviors & $\mathrm{P}$ \\
\hline Cultural socialization (Latinx subsample only) & $\mathrm{P}$ \\
\hline $\begin{array}{l}\text { Parenting (questionnaires and coded from } \\
\text { videotaped parent-child interactions) }\end{array}$ & $\mathrm{P}, \mathrm{Obs}$ \\
\hline \multicolumn{2}{|l|}{ Parent health } \\
\hline Parent depression and anxiety & $\mathrm{P}$ \\
\hline Parent alcohol and drug use & $\mathrm{P}$ \\
\hline Parent sleep & $\mathrm{P}, \mathrm{O}$ \\
\hline Parent pain & $\mathrm{P}, \mathrm{O}$ \\
\hline $\begin{array}{l}\text { Parent general health (BMI, lung capacity, grip } \\
\text { strength, balance, chronic and acute pain) }\end{array}$ & $P, O$ \\
\hline \multicolumn{2}{|l|}{ Daily context, affect and health } \\
\hline Stress and coping & $\mathrm{P}$ \\
\hline Social media use & $\mathrm{P}$ \\
\hline Affect & $\mathrm{P}$ \\
\hline Sleep timing and length & $\mathrm{P}, \mathrm{O}$ \\
\hline Bedtime behavioral routines & $\mathrm{P}$ \\
\hline Diet and nutrition & $\mathrm{P}$ \\
\hline \multicolumn{2}{|l|}{ Puberty, sleep, pain and health } \\
\hline Puberty & $\mathrm{P}, \mathrm{C}$ \\
\hline Body mass index & 0 \\
\hline Lung capacity & 0 \\
\hline Grip strength & 0 \\
\hline Balance & 0 \\
\hline $\begin{array}{l}\text { General health, chronic illness, service utilization } \\
\text { and medication use }\end{array}$ & $P, C$ \\
\hline Sleep duration and quality & $\mathrm{P}, \mathrm{O}$ \\
\hline Activity and exercise & $\mathrm{O}, \mathrm{C}$ \\
\hline Diurnal cortisol & 0 \\
\hline Chronic pain & $\mathrm{P}, \mathrm{C}$ \\
\hline Acute pain, intensity and unpleasantness & $\mathrm{P}, \mathrm{C}, \mathrm{O}$ \\
\hline $\begin{array}{l}\text { Emotions, temperament and symptoms of } \\
\text { psychopathology }\end{array}$ & $\mathrm{P}, \mathrm{C}, \mathrm{Obs}$ \\
\hline \multicolumn{2}{|l|}{ Executive functioning } \\
\hline Continuous performance task & 0 \\
\hline Flanker task & 0 \\
\hline
\end{tabular}

Table 1. (Continued)

\begin{tabular}{ll}
\hline Construct & Source \\
\hline Digit span forward and backward & $\mathrm{O}$ \\
\hline Attentional focusing & $\mathrm{P}$ \\
\hline Inhibitory control & $\mathrm{P}$ \\
\hline $\begin{array}{l}\text { School Liking and Academic Competence } \\
\text { (grades and tests of achievement) }\end{array}$ & $\mathrm{P}, \mathrm{T}, \mathrm{C}, \mathrm{O}$ \\
\hline
\end{tabular}

Note: 1 and 2.5 year assessments are described in Lemery-Chalfant et al. (2013). $\mathrm{P}=$ parent (mothers and fathers); $\mathrm{T}=$ Teacher; Obs $=$ Observed; $\mathrm{C}=$ Child; $\mathrm{O}=$ Objective.

contributions to impulsivity and sleep. Additive genetic correlations were .24 for associations with sleep duration and .23 for sleep efficiency (Miadich et al., 2018).

\section{Moderation of Genetic and Environmental Influences on Executive Functioning}

A common factor of executive functioning has been found to be highly heritable in childhood (Engelhardt et al., 2015), though little is known regarding variable etiologies of executive functioning across contexts. We examined whether early-life family stress and SES moderated the genetic and environmental influences on executive functioning at 8 years (Rea-Sandin et al., 2018). Measures of executive functioning included computerized continuous performance and flanker tasks, digit span forward and backward, and parent-reported attentional focusing and inhibitory control. The measures were included in a principal component analysis to index a common executive functioning factor. As family stress increased, the role of the shared environment increased for inhibitory control, $\Delta \chi^{2}(2)=6.14, p=.05$. The role of the shared environment also increased for digit span backward as SES increased, $\Delta \chi^{2}(2)=1.86, p=.40$. Although moderation was observed for select executive functioning variables, the etiology of the common executive functioning factor was not moderated by early family stress or SES, suggesting that etiology is constant across stressful childhood environments.

We also examined whether familism, an important cultural value characterized by valuing obedience and respect for family members, moderated the etiology of executive functioning in middle childhood (Rea-Sandin et al., 2019). Although traditionally endorsed by Mexican American individuals, we found that other American ethnic groups ascribe to familism values as well. Results indicated that the nonshared environmental influence on common executive functioning increased as familism increased, $\Delta \chi^{2}(2)=3.86, p=.15$. Our findings highlight the need for genetically informed research to consider the role of culture on the genetic and environmental influences on children's health.

\section{Moderation of Genetic and Environmental Influences on Parenting}

Traditional examinations of parenting as a causal factor influencing children's development diminish the fact that children's heritable traits affect parenting behaviors, representing an evocative gene-environment correlation (Avinun \& Knafo, 2014). We examined whether the degree of genetic and environmental influence on observed negative parenting practices varied as a function of SES and found that heritability was greatest at the extremes of SES and negligible at average levels, whereas variance attributable to shared 
environmental influence declined as SES increased, $\Delta \chi^{2}(1)=1.54$, $p=.21$. Total variance in negative parenting also decreased as SES increased (Oro et al., 2019). Results suggest that factors operating at both the low and high extremes of SES may contribute to parents being more reactive to their children's heritable traits.

\section{Children's Chronic Pain, Acute Pain and Internalizing Symptoms}

There is a robust area of research examining both the etiology of and relations among chronic pain, acute pain and mood disorder symptoms in adulthood; however, parallel research in childhood is quite limited. With a partial sample, we examined the extent to which children's chronic pain (primary caregiver report), acute pain (duration of cold pressor task) and internalizing symptoms (self-report) were genetically and environmentally influenced as well as phenotypically related. Results yielded moderate to high estimates of heritability, with $43 \%, 73 \%$ and $34 \%$ of the variance in chronic pain, acute pain and internalizing symptoms explained by genetic factors, respectively. Phenotypic correlations indicated that children's chronic pain, acute pain and internalizing symptoms were relatively independent, a departure from the adult literature warranting further examination from a developmental perspective (preliminary analysis, 2019).

\section{Pain Transmission within Families}

Several studies report evidence for the familial aggregation of pain symptoms, but these studies overwhelmingly focus on adult relatives and offspring. We examined associations between primary caregivers' and children's pain and internalizing symptoms. Results indicated significant within domain correlations, but not across domains. Intergenerational correlations for chronic pain, acute pain and internalizing were $.21(p<.001), .22(p<.001)$ and $.25(p<.001)$, respectively (preliminary analysis, 2019). These findings suggest that pain transmission within families occurs as early as middle childhood.

These preliminary findings attest to the critical influence of the sociocultural and socioeconomic contexts on health in middle childhood, both directly and as a moderator of genetic and environmental etiology. However, data collection is ongoing so important longitudinal models have yet to be tested. Future analyses will elucidate developmental cascades capturing dynamic progressions across the mental and physical health domains.

\section{Future Directions}

Currently, we are seeking funding for assessments in adolescence, focused on how the dynamic developmental processes of puberty, sleep and general health assessed at 8-12 years predict inflammation and mental health at age 14 years. Our extensive environmental assessment includes Geographic Information Systems coding of neighborhoods, as well as daily assessment of frequency and duration of media use.

\section{Conclusion}

The longitudinal Arizona Twin Project has been ongoing since 2007, with annual in-depth assessments across middle childhood funded by the US National Institutes of Health (R01HD079520 and R01HD086085). Twins were recruited through birth records, with significant representation of Latinx, as well as White participants. Multiple aspects of the prenatal, infancy and childhood physical and sociocultural environments have been assessed, creating an opportunity to study stability and change, geneenvironment correlation and moderated heritability. In-depth phenotyping of physical and mental health outcomes allows comparison across methods. We welcome collaboration with other twin researchers and panels. Results contribute to a growing area of research on the intersection of cultural and genetic approaches to the study of physical and mental health.

Acknowledgments. Support for this research was provided by the US Eunice Kennedy Shriver National Institute of Child Health and Human Development (R01HD079520 and R01HD086085). We also wish to extend our appreciation to the Arizona Twin Project students and staff, and the participating twins and families.

\section{References}

Avinun, R., \& Knafo, A. (2014). Parenting as a reaction evoked by children's genotype: A meta-analysis of children-as-twins studies. Personality and Social Psychology Review, 18, 87-102.

Bradley, R. H., Corwyn, R. F., Caldwell, B. M., Whiteside-Mansell, L., Wasserman, G. A., \& Mink, I. T. (2000). Measuring the home environments of children in early adolescence. Journal of Research on Adolescence, 10, 247-288.

Breitenstein, R.S. (2019). Genetic and environmental influences on associations among multiple sleep parameters, weight indicators and weight status, and effortful control in young twins. Unpublished doctoral dissertation, Arizona State University, AZ.

Breitenstein, R. S., Doane, L. D., Clifford, S., Miadich, S. A., \& LemeryChalfant, K. (2018). Genetic and environmental associations between objective sleep and weight indicators in 8-year-old twins [Abstract]. Behavior Genetics, 48, 460.

Breitenstein, R. S., Doane, L. D., \& Lemery-Chalfant, K. (2019). Children's objective sleep assessed with wrist-based accelerometers: Strong heritability unique from parent-reported sleep. Manuscript under review.

Conners, C. K. (2000). Conners' Continuous Performance Test II: Technical guide. Toronto, Canada: Multi-Health Systems. Retrieved June 15, 2015, from http://www.pearsonclinical.co.uk/Psychology/ChildMentalHealth/ChildADD ADHDBehaviour/ConnersContinuousPerformanceTestIIVersion5forWin dows(CPTIIV5)/PDFReports/Profile.pdf

Dionne, C. E., Dunn, K. M., Croft, P. R., Nachemson, A. L., Buchbinder, R., Walker, B. F., ... Hartvigsen, J. (2008). A consensus approach toward the standardization of back pain definitions for use in prevalence studies. Spine, 33, 95-103.

Drossman, D. A. (2016). Functional gastrointestinal disorders: History, pathophysiology, clinical features, and Rome IV. Gastroenterology, 150, 1262-1279.

Dworkin, S. F., Von Korff, M. R., \& LeResche, L. (1992). Epidemiologic studies of chronic pain: A dynamic-ecologic perspective. Annals of Behavioral Medicine, 14, 3-11.

Engelhardt, L. E., Briley, D. A., Mann, F. D., Harden, K. P., \& Tucker-Drob, E. M. (2015). Genes unite executive functions in childhood. Psychological Science, 26, 1151-1163.

Eriksen, B. A., \& Eriksen, C. W. (1974). Effects of noise letters upon the identification of a target letter in a nonsearch task. Attention, Perception, \& Psychophysics, 16, 143-149.

Forget-Dubois, N., Perusse, D., Turecki, G., Girard, A., Billette, J., Rouleau, G., \& Tremblay, R. E. (2003). Diagnosing zygosity in infant twins: Physical similarity, genotyping, and chorionicity. Twin Research, 6, 479-485.

Goldsmith, H. H. (1991). A zygosity questionnaire for young twins: A research note. Behavior Genetics, 21, 257-269.

Gruber, R., Cassoff, J., Frenette, S., Wiebe, S., \& Carrier, J. (2012). Impact of sleep extension and restriction on children's emotional lability and impulsivity. Pediatrics, 130, e1155-e1161.

Headache Classification Subcommittee of the International Headache Society. (2004). The International Classification of Headache Disorders: 2nd edition. Cephalalgia, 24, 9-160. 
Hicks, C. L., von Baeyer, C. L., Spafford, P. A., van Korlaar, I., \& Goodenough, B. (2001). The Faces Pain Scale - Revised: Toward a common metric in pediatric pain measurement. Pain, 93, 173-183.

Keyes, K.M., Maslowsky, J., Hamilton, A., \& Schulenberg, J. (2015). The great sleep recession: Changes in sleep duration among U.S. adolescents, 1991-2012. Pediatrics, 135, 460-468.

Lemery-Chalfant, K., Clifford, S., McDonald, K., O'Brien, T. C., \& Valiente, C. (2013). Arizona twin project: A focus on early resilience. Twin Research and Human Genetics, 16, 404-411.

Magee, L., \& Hale, L. (2012). Longitudinal associations between sleep duration and subsequent weight gain: A systematic review. Sleep Medicine Reviews, 16, 231-241.

McGrath, P. A., De Veber, L., \& Hearn, M. T. (1985). Multidimensional pain assessment in children. Advances in Pain Research and Therapy, 9, 387-393.

Miadich, S., Doane, L. D., Breitenstein, R. S., Clifford, S., Davis, M. C., \& Lemery-Chalfant, K. (2018). The genetic and environmental associations between sleep and impulsivity in middle childhood. Behavior Genetics, 48, 496-496.

Mueller, S. T. (2013). The Psychology Experiment Building Language (Version 0.13) [Software]. http://pebl.sourceforge.net

Oro, V., Doane, L., \& Lemery-Chalfant, K. (2019). The role of evocative geneenvironment correlation in observed negative parenting: Moderation by socioeconomic status. [Abstract]. Behavior Genetics, 49, 553-553.
Patalay, P., \& Gage, S. H. (2019). Changes in millennial adolescent mental health and health-related behaviours over 10 years: A population cohort comparison study. International Journal of Epidemiology. doi:10.1093/ije/ dyz006

Price, T. S., Freeman, B., Craig, I. W., Petrill, S. A., Ebersole, L., \& Plomin, R. (2000). Infant zygosity can be assigned by parental report questionnaire data. Twin Research, 3, 129-133. doi:10.1375/twin.3.3.129

Rea-Sandin, G., Clifford, S., Doane, L. D., \& Lemery-Chalfant, K. (2018). Genetic and environmental influences on executive functioning in middle childhood: the role of early adversity. [Abstract] Behavior Genetics, 48, 508-508.

Rea-Sandin, G., Doane, L. D., Gonzales, N., \& Lemery-Chalfant, K. (2019). Cultural differences in genetic and environmental influences on executive functioning in middle childhood. Presentation at the Society for Research in Child Development Conference, Baltimore, Maryland.

von Baeyer, C. L., Piira, T., Chambers, C. T., Trapanotto, M., \& Zeltzer, L. K. (2005). Guidelines for the Cold Pressor Task as an experimental pain stimulus for use with children. Journal of Pain, 6, 218-227.

Wechsler, D. (2003). Wechsler Intelligence Scale for Children (4th ed.). San Antonio, TX: The Psychological Corporation.

Wolfe, F., Clauw, D. J., Fitzcharles, M. A., Goldenberg, D. L., Katz, R. S., Mease, P., \& Yunus, M. B. (2010). The American College of Rheumatology preliminary diagnostic criteria for fibromyalgia and measurement of symptom severity. Arthritis Care \& Research, 62, 600-610. 